\title{
The influence of aging treatments on sulfide stress corrosion cracking of PH 13-8 Mo steel welds
}

\author{
L.W. Tsay ${ }^{\text {a,* }}$, H.H. Chen ${ }^{\text {a }}$, M.F. Chiang ${ }^{\text {b,1 }}$, C. Chen ${ }^{\text {b, } 1}$ \\ ${ }^{a}$ Institute of Materials Engineering, National Taiwan Ocean University, Keelung 202, Taiwan, ROC \\ ${ }^{\mathrm{b}}$ Materials Science \& Engineering Department, National Taiwan University, Taipei 106, Taiwan, ROC
}

Received 6 December 2005; accepted 10 December 2006

Available online 24 December 2006

\begin{abstract}
Slow displacement rate tensile tests were carried out to study sulfide stress corrosion cracking (SSCC) of $\mathrm{PH}$ 13-8 Mo stainless steel welds in a saturated $\mathrm{H}_{2} \mathrm{~S}$ solution. The welds aged in the temperature range of $482-593{ }^{\circ} \mathrm{C}$ were susceptible to SSCC; the fracture surfaces revealed mainly quasi-cleavage fractures after notched tensile tests. However, the SSCC susceptibility in terms of the percentage loss of the notched tensile strength (NTS) of the welds was dependent on the aging treatment. The SSCC resistance and the austenite content of the welds increased with the aging temperatures. The presence of greater amounts of austenite, mainly reverted austenite, in the W1100 specimen (the weld aged at $1100^{\circ} \mathrm{F}$ or $593^{\circ} \mathrm{C}$ ) than that in other aged specimens could account for its lower hardness and better SSCC resistance. On the other hand, the AW (as-welded) specimen containing a small amount of retained austenite films in a soft matrix exhibited a slightly improved SSCC resistance than that in the W1100 specimen. The lower hardness of the AW specimen was owing to the absence of fine coherent precipitates, leading to a reduced local stress and an enlarged plastic zone located in front of the notch in the test. With lower hardness, the local stress would also be lower and less likely to exceed some critical stress for failure in the saturated $\mathrm{H}_{2} \mathrm{~S}$ solution. For the aged specimens, the hardness/strength level and the amount of reverted austenite were the important factors that affect SSCC susceptibility.
\end{abstract}

(C) 2006 Elsevier Ltd. All rights reserved.

Keywords: A. Stainless steel; B. STEM; C. Hydrogen embrittlement; C. Welding

\footnotetext{
* Corresponding author. Tel.: +886 234 633192; fax: +886 224625324.

E-mail address: b0186@mail.ntou.edu.tw (L.W. Tsay).

${ }^{1}$ Fax: +886223634562.
} 


\section{Introduction}

The deleterious effects of hydrogen on mechanical properties are reported to cause premature failures of some high strength steels [1-3]. The presence of hydrogen reduces the grain boundary cohesive strength [4] and particularly, the fracture stress of high-strength steels $[5,6]$. It is generally agreed that the resistance to hydrogen embrittlement of steels depends on the microstructure, strength level, and hydrogen concentration [7-11]. In the presence of a notch, hydrogen has a tendency to move towards a region of high hydrostatic stress [12] and becomes more aggressive as an embrittling agent due to accentuated assault with increased stress concentrations [5,13]. A systematic loss in fracture stress in hydrogen with an increase in notch severity has been documented [5,13]. Sulfide stress corrosion cracking (SSCC) is a typical example of hydrogen embrittlement under severe conditions [14]. It is also acknowledged that the strength level, which is directly related to the hardness, is an important factor in determining SSCC susceptibility of steel. As a result, several high strength steels are used in over-aged conditions for reduced susceptibility with regard to the hydrogen embrittlement [15].

Modified 13\% Cr martensitic stainless steels, with low carbon and varying Mo contents, have been used for the construction of oil and gas transmission lines owing to their high strength, better weldability and excellent resistance to $\mathrm{CO}_{2}$ corrosion [16-18]. PH 13$8 \mathrm{Mo}$ steel (13Cr-8Ni-2Mo) has a higher Ni content than this category of steels, with the addition of approximately $1 \% \mathrm{Al}$ to form intermetallic particles in the aging treatment. It combines with high strength/hardness along with good resistance to general corrosion and stress-corrosion cracking. PH 13-8 Mo steel has been used for valve parts, fittings, aircraft components and petrochemical applications. In comparison with other alloys with similar strength levels, the SSCC resistance is reported as - PH 13-8 Mo, PH 174, PH 15-5, and 410 stainless steels in the descending order [19]. The presence of more austenite in the PH 13-8 Mo steel as compared to others is responsible for the improved resistance [19]. In the solution-treated condition, the steel comprises of irregular blocky units of lath martensite and a small amount of retained austenite [20]. When aging is carried out in the temperature range of 450 to $620^{\circ} \mathrm{C}$, the uniform precipitation of round $\mathrm{NiAl}$ particles apparently results in the hardening of the steel [20]. In addition, the formation of reverted austenite tends to lower the hardness of the over-aged specimens [20,21]. A substantial improvement in the SSCC of the PH 13-8 Mo steel can be obtained by aging at $620{ }^{\circ} \mathrm{C}$ or higher, owing to the extensive formation of reverted austenite in the structure [22].

Slow extension rate tensile tests are suitable to evaluate the SSCC of steels in the $\mathrm{H}_{2} \mathrm{~S}$ saturated NACE solution $[23,24]$. The effect of hydrogen embrittlement on the mechanical properties and fracture behaviour of $\mathrm{PH} 13-8$ Mo steel has been the subject of several studies [22,25-27]; however, less attention has been focused on its welds. In this study, the effect of aging treatments on the SSCC susceptibility of PH 13-8 Mo welds was conducted on notched tensile specimens in the saturated $\mathrm{H}_{2} \mathrm{~S}$ solution. The fracture surfaces of distinct specimens were examined by scanning electron microscopy (SEM) and the associated fracture modes were identified. In addition, the detailed microstructure was studied using transmission electron microscope (TEM) and related to the SSCC susceptibility of the welds. 


\section{Material and experimental procedures}

The chemical composition in weight percent of the PH 13-8 Mo stainless steel used in this investigation was $12.56 \mathrm{Cr}, 8.11 \mathrm{Ni}, 2.12 \mathrm{Mo}, 0.05 \mathrm{C}, 0.04 \mathrm{Si}, 0.05 \mathrm{Mn}, 0.006 \mathrm{P}, 0.003 \mathrm{~S}$, $0.006 \mathrm{~N}, 1.07 \mathrm{Al}$, and balance Fe. The alloy sheet of $4.1 \mathrm{~mm}$ thick was solution-treated in an inert environment at $930^{\circ} \mathrm{C}\left(1700^{\circ} \mathrm{F}\right)$ for $40 \mathrm{~min}$ and then air-cooled to room temperature. Bead-on-plate laser welding was performed on solution-treated specimens using a Rofin-Sinar $5 \mathrm{~kW} \mathrm{CO}$ laser to achieve full-penetration welds. The welding parameters used in the experiment are listed in Table 1. At the same strength level, a higher SSCC susceptibility is established for PH 13-8Mo and T-200 maraging steels in the under-aged condition as compared to that of the over-aged specimens $[28,29]$. Therefore, the PH 13-8 Mo welds were not heat treated to the under-aged condition in the present investigation. The aging treatments were performed on laser welds at $482^{\circ} \mathrm{C}\left(900{ }^{\circ} \mathrm{F}\right), 538^{\circ} \mathrm{C}\left(1000{ }^{\circ} \mathrm{F}\right)$, and $593{ }^{\circ} \mathrm{C}\left(1100^{\circ} \mathrm{F}\right)$ for $4 \mathrm{~h}$; the corresponding specimens were designated as the W900, W1000 and W1100 specimens, respectively.

The dimensions of the notched tensile specimens utilized in this study are shown in Fig. 1. The double-edge notched specimens (Fig. 1), with a notch radius of about $100 \mu \mathrm{m}$, were obtained by using an electrode-discharge wire cutter. Notched tensile strength (NTS) can be calculated from the maximum tensile load divided by the cross-sectional area $\left(4 \times 6 \mathrm{~mm}^{2}\right)$ between the two notches of the specimen. Ordinary notched tensile tests were performed at room temperature under a constant crosshead displacement rate of $0.75 \mathrm{~mm} / \mathrm{min}$ in laboratory air. On the other hand, the effect of hydrogen embrittlement on NTS was evaluated by installing the specimen in a Teflon chamber with saturated $\mathrm{H}_{2} \mathrm{~S}$ solution (NACE TM0177-90) under at a displacement rate of $0.0075 \mathrm{~mm} / \mathrm{min}$. The change of acidity (from $\mathrm{pH} 2.9$ to 3.3 ) during notched tensile tests in the saturated $\mathrm{H}_{2} \mathrm{~S}$ solution also met the requirement of the standard. The NTS results were the average of at least three specimens for each testing condition. The SSCC susceptibility of various specimens can be expressed as the percentage loss of NTS after hydrogen-charging as given below:

$$
\text { NTS loss }(\%)=\frac{\text { NTS (in air) }- \text { NTS }\left(\text { in } \mathrm{H}_{2} \mathrm{~S}\right)}{\text { NTS (in air) }}
$$

The X-ray diffraction (XRD) method was also employed to compare the relative amount of austenite in the welds. The surface to be examined was along the central plane of laser welds, i.e. the welded specimen was cut along the centerline; this central plane had

Table 1

Laser welding parameters employed in this work

\begin{tabular}{ll}
\hline Laser power & $3250 \mathrm{~W}$ \\
Travel speed & $750 \mathrm{~mm} / \mathrm{min}$ \\
Focal lens & $\mathrm{Cu} \mathrm{mirror}$ \\
Focal length & $200 \mathrm{~mm}$ \\
Focal point & $0.5 \mathrm{~mm}$ below the surface \\
Plasma-assisted gas flow rate & $201 / \mathrm{min} \mathrm{He}$ \\
Shielding gas flow rate & $151 / \mathrm{min} \mathrm{Ar}$ \\
Backing gas flow rate & $151 / \mathrm{min} \mathrm{Ar}$ \\
\hline
\end{tabular}



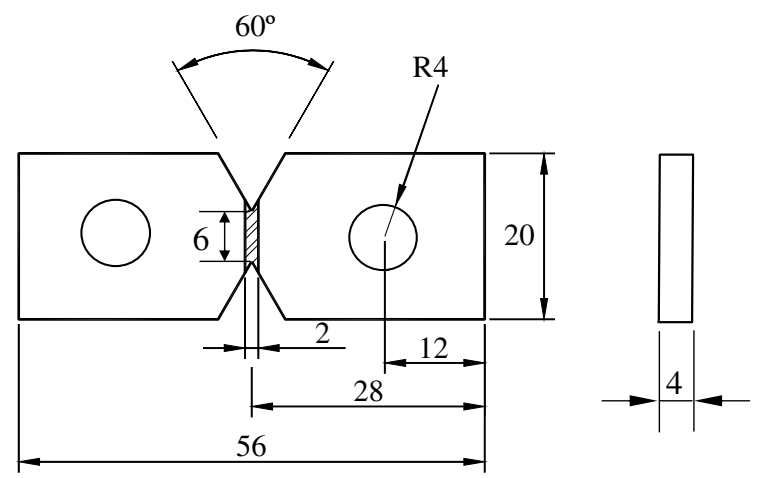

Fig. 1. Configuration of the notched tensile specimen used in the experiment.

an area of approximately $10 \times 4 \mathrm{~mm}^{2}$. Since the preferred orientation was the same for all welded specimens, so that the relative amount of austenite could be compared directly from the XRD patterns of the welds. The tensile-fractured specimens were examined by a Hitachi S4100 SEM, with emphasis on the crack initiation sites and regions indicating a change in fracture appearance. For detailed microstructural observations, the TEM specimens were sectioned into thin slices within the fusion zone of the welds and and subsequently examined using either a JEOL-2000 EX or a Philips Tecnai F30 TEM.

\section{Results and discussion}

\subsection{Microhardness and microstructure}

Fig. 2 reveals a typical weld shape and microhardness profiles across the weld metal of laser welds that were aged at different temperatures. Clearly, the low heat input of the laser welding would result in the formation of a narrow heat-affected zone in the weld. As shown in Fig. 2b, both the base metal and the weld metal exhibit a similar trend of the variation in hardness with aging temperatures. In general, the hardness of the weld metal was slightly lower than its neighbouring base metal for all the welds. It could be attributed to the coarse-grained structure of the weld metal. The results also indicated that the weld aged at $482{ }^{\circ} \mathrm{C}$ (peak-aged) had the highest hardness, whereas the as-welded specimen exhibited the lowest hardness among specimens. Aging at a temperature higher than $482{ }^{\circ} \mathrm{C}$, the hardness of the weld and base metals decreased with increasing the aging temperature. Moreover, a remarkable decrease in the hardness occurred for a weld aged at a temperature above $593{ }^{\circ} \mathrm{C}$. Thus, the welds could be roughly divided into two groups (Fig. 2b) according to their hardness values. The W900 and W1000 specimens were in the higher hardness group, while the AW and W1100 specimens belonged to the lower one.

Fig. 3 is optical micrographs showing the microstructure of solution-treated $\mathrm{PH} \mathrm{13-8}$ Mo base metal and its laser weld in the as-welded condition. It can be seen the coarse columnar dendrite in the weld metal (Fig. 3a), in contrast to the equiaxed grain in the base metal (Fig. 3b). The TEM examinations revealed that the AW specimen consisted of lath martensite and film-like retained austenite at the lath boundaries (Fig. 4a). The film-like morphology of austenite had been confirmed by tilting the specimen in the TEM exami- 

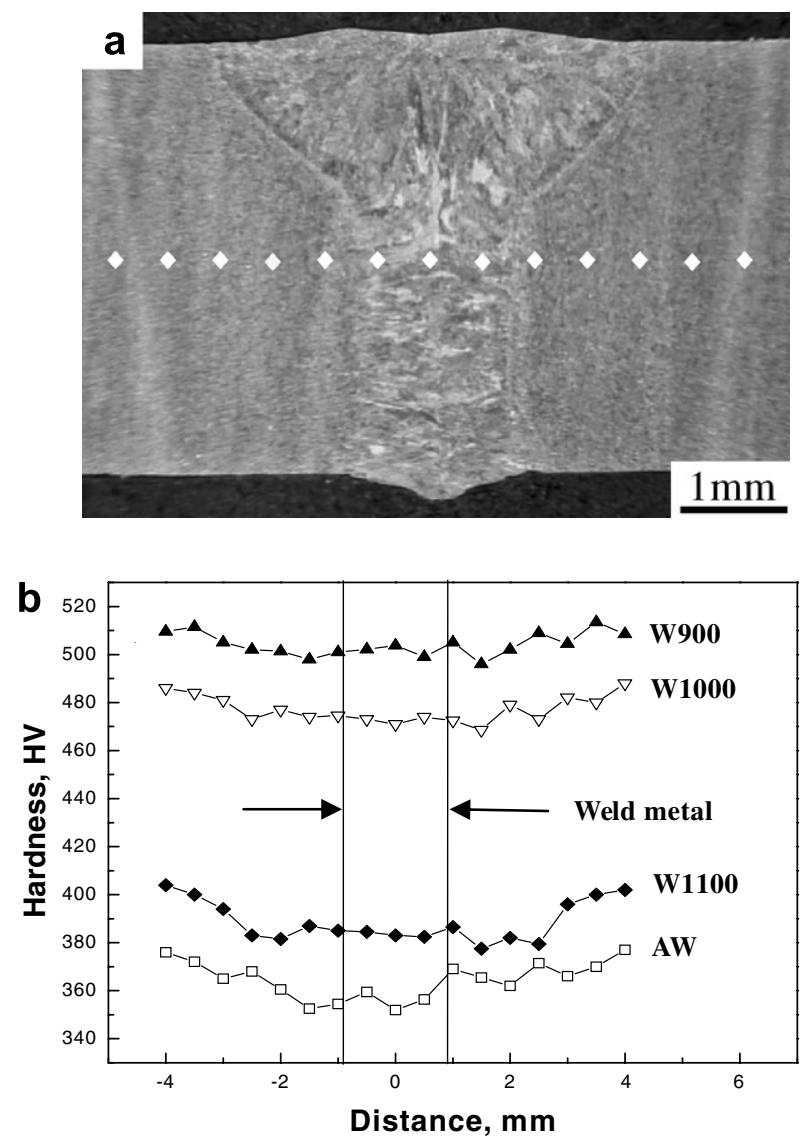

Fig. 2. PH 13-8 Mo laser welds: (a) the typical weld shape and (b) microhardness distribution of the welds aged at various temperatures.

nation. After the aging treatments, the formation of coherent and fine precipitates within the matrix caused a tremendous increase in hardness of the W900 and W1000 specimens. In the meantime, a gradual change in the austenite morphology along the lath boundaries was observed in these specimens; the morphology of austenite tended to be less film-like with the formation of certain small islands (Fig. 4b).

In case of the W1100 specimen, a significant change in the austenite morphology was found at the lath boundaries. Granular austenite was clearly observed at some lath boundaries (Fig. 5a). Furthermore, small reverted austenite particles were formed within the interior of the martensite matrix (Fig. 5b) of the W1100 specimen. The existence of a substantial amount of reverted austenite was responsible for the remarkable decrease in the hardness of the W1100 specimen. Since the reverted austensite formed at the lath boundaries was difficult to distinguish from the existing retained austensite; no effort was made to distinguish them at these boundaries. Conversely, the reverted austenite formed within a martensite matrix could be clearly identified. For the weld aged at $593{ }^{\circ} \mathrm{C}$, i.e. the W1100 specimen, the coherency of fine precipitates (Fig. 5c) rich in $\mathrm{Ni}$ and $\mathrm{Al}$ (Fig. 5d) could still be maintained. This is in agreement with the fact that NiAl 

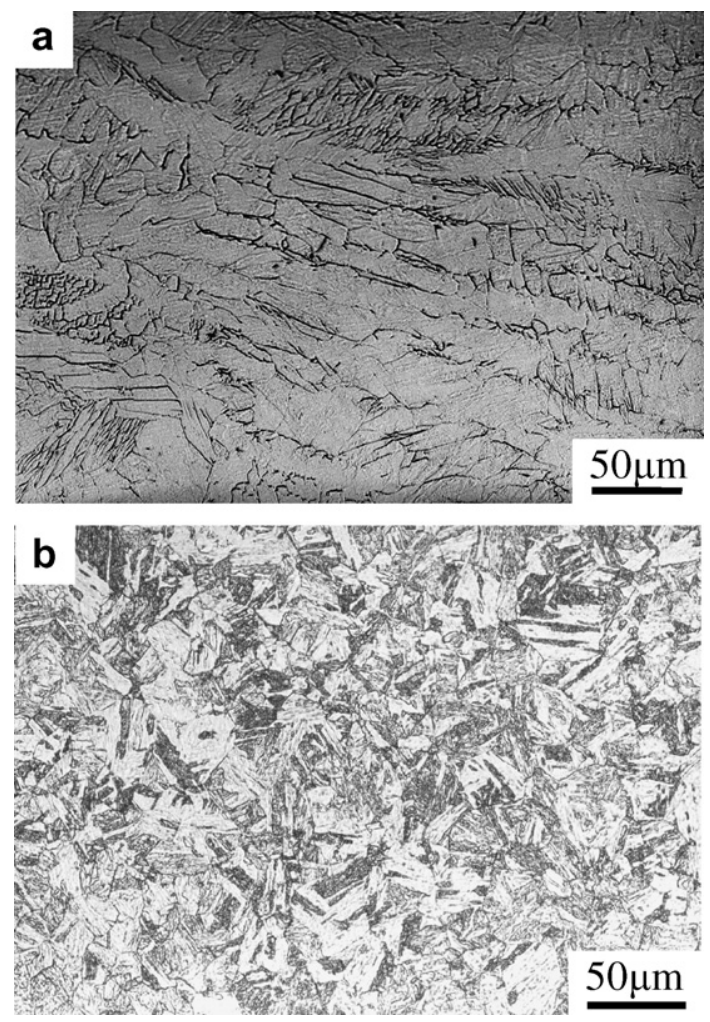

Fig. 3. Optical micrographs showing microstructures of (a) the weld metal in the as-welded condition and (b) the solution-treated base metal.

particles are resistant to coarsening and maintain perfect coherency with matrix even over-

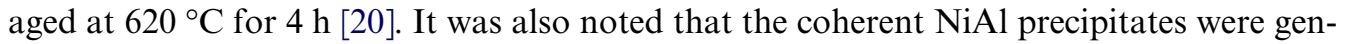
erally not spherical and appeared to form moderately elongated particles.

The relative amount of austenite in the weld also increased with increasing the aging temperature as confirmed by the XRD measurements (Fig. 6). The AW and W900 specimens did not reveal austenite peaks, presumably because the austenite content was less than $4 \mathrm{wt} \%$ that is the detectable limit of the XRD equipment. Small austenite peaks of (111) and (200) could be seen for the W1000 specimen $(\sim 5 \%)$, and the intensity of such peaks increased appreciably for the W1100 specimen $(\sim 12 \%)$. The relative amount of austenite in the welds as determined by XRD was consistent with the TEM observations. Although the AW specimen contained less austenite than the other aged specimens, the presence of the film-like austenite in a soft and precipitate-free matrix was expected to reduce the SSCC susceptibility. This topic is further discussed in the following sections.

\subsection{Notched tensile strength}

The NTS values of $\mathrm{PH} 13-8$ Mo welds tested in the air and the saturated $\mathrm{H}_{2} \mathrm{~S}$ solution are shown in Fig. 7, in which the NTS values of base metal specimens in air are also 

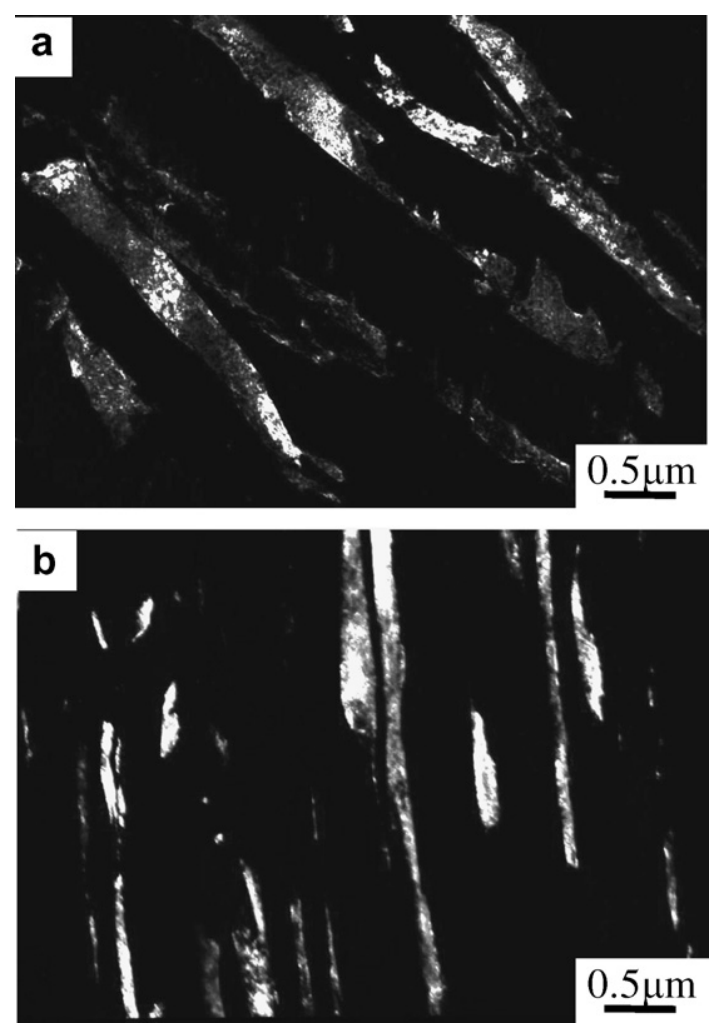

Fig. 4. TEM dark-field images of the (a) AW and (b) W900 specimens using austenite reflections.

included for comparison. The weld metal had a slightly lower NTS in air than the unwelded specimen or the base metal, regardless of the aging temperatures. Generally, the trend of variation of the NTS with the aging temperature was similar to that of the hardness of specimens. The W900 specimen had the highest, while the AW specimen had the lowest NTS in air among the welds. The higher NTS could be linked to the higher hardness of the specimens, and vice versa.

In the saturated $\mathrm{H}_{2} \mathrm{~S}$ solution, a considerable reduction in NTS was noticed for all the welds, indicating a high susceptibility to SSCC. For high strength materials, the high local stress at the crack tip was more likely to exceed the critical fracture stress, leading to a premature fracture. It was also expected that the critical fracture stress would decrease under the influence of hydrogen embrittlement. It is generally agreed that a high strength material is associated with a small plastic zone in front of the notch. As a result, the high SSCC susceptibility of the W900 and W1000 (the higher hardness group) specimens as reflected by the high NTS loss could be related to the high local stress and the small plastic zone of the notched specimens in the test. In contrast, a better SSCC resistance of the AW and W1100 (the lower hardness group) specimens could be attributed to the low local stress and the large plastic zone in front of the notch in the test. An enlaged plastic zone also implied that more hydrogen could be tolerated in the zone before reaching a critical concentration for the embrittlement. 

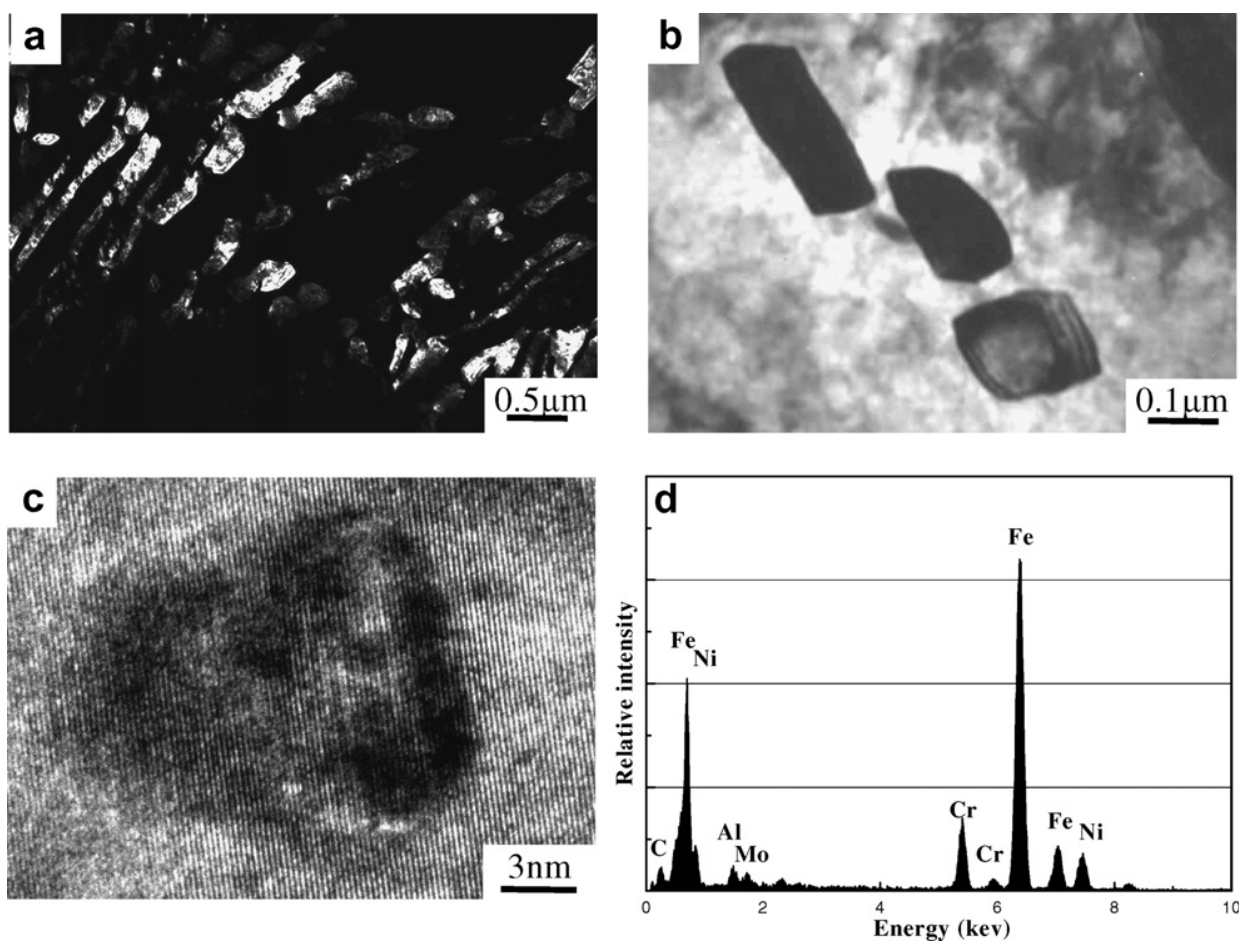

Fig. 5. TEM micrographs of the W1100 specimen: (a) dark-field image of granular austenite at lath boundaries; (b) small reverted austenite islands within martensite matrix; (c) lattice image of a NiAl coherent precipitate and (d) the associated EDS analysis of the particle in (c).

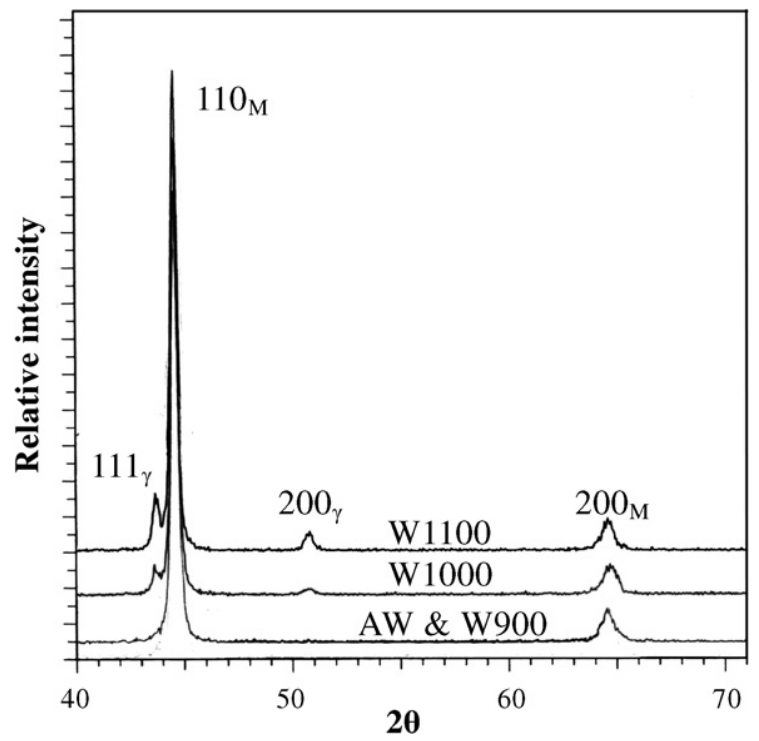

Fig. 6. XRD results of the welds. Note that the diffraction patterns of the AW and W900 specimens are the same. 


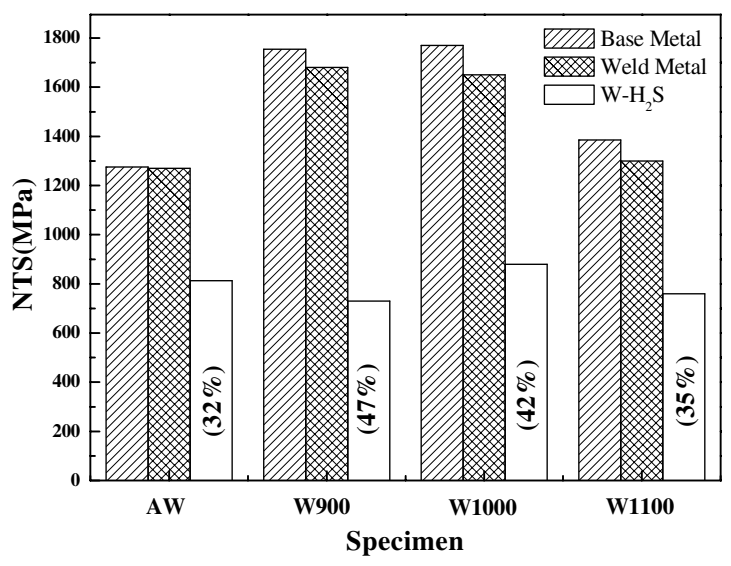

Fig. 7. Notch tensile strength (NTS) of $\mathrm{PH} 13-8$ Mo laser welds tested in air and saturated $\mathrm{H}_{2} \mathrm{~S}$ solution. Note that the NTS of the base metal (BM) is also included for comparison and the percentage within parentheses indicates the NTS loss of the weld metal (WM) in saturated $\mathrm{H}_{2} \mathrm{~S}$ solution.

In the previous studies, distinct microstructures with various hydrogen permeation properties can be correlated to the hydrogen embrittlement susceptibility of the material $[9,11,30]$. Decreasing the number of weak traps and increasing the number of strong traps (such as the interface between austenite and the matrix) can improve the hydrogen embrittlement resistance of the steels [30-32]. Therefore, a significantly increased austenite content accompanied with decreasing hydrogen permeability would reduce the SSCC susceptibility of the steel. This could be the case for the W1100 specimen ( $12 \%$ austenite), and the role of austenite could also be in relation to crack arrest as discussed elsewhere [33-35].

Microstructurally, the major difference between the AW and the W900 specimens was the absence of $\mathrm{NiAl}$ coherent precipitates in the former. The presence of coherent precipitates caused a significant increase in the hardness/ strength of the W900 specimen, which would lead to a high local stress and a reduced plastic zone in front of the crack tip during notched tensile tests. Coherent particles were considered as weak traps and did not facilitate the reduction of hydrogen embrittlement susceptibility of the material. Consequently, the peak-aged W900 specimen had the least SSCC resistance among the specimens being tested. As the aging temperature increased, e.g. in the W1000 specimen, the coherent precipitates remained almost constant in the matrix. Nevertheless, a decrease in the hardness and a slight increase in the reverted austenite of the W1000 specimen would also reflect a minor improvement in the SSCC resistance of the W900 specimen.

The AW specimen contained considerably less amount of austenite than the W1100 specimen (4\% vs. 12\%); however, it exhibited the lowest NTS loss in all the welded specimens in the experiment. Low local stress at the notch tip associated with a soft AW specimen (that demonstrated the lowest hardness among the specimens) could account for a better SSCC resistance. On the other hand, the austenite films in the AW specimen provided enormous interfacial areas to trap hydrogen and decreased the diffusivity of the hydrogen. It has been reported that the NTS loss in the saturated $\mathrm{H}_{2} \mathrm{~S}$ solution is dependent on the displacement rate for T-200 maraging and $\mathrm{PH} 13-8$ Mo steels [28,29]; a decreased displacement rate (from 0.0075 to $0.0015 \mathrm{~mm} / \mathrm{min}$ ) results in the increased 
NTS loss. The increased NTS loss at a lower displacement rate implied that the embrittlement is time dependent. Apparently, the retardation of hydrogen diffusion (lowered the effective diffusion rate) to the strained region would also help to reduce the SSCC susceptibility of the specimen. It should be noted that residual stresses may cause cracking in welds without any applied loads in a hostile environment. Consequently, the welds are often not to be used in the as-welded condition for most applications. A postweld (stress relief) heat treatment at a temperature of approximately $600{ }^{\circ} \mathrm{C}$ is necessary for the PH 13-8 Mo welds in this regard.

\subsection{Fracture morphology}

Fig. 8 shows the macroscopic fracture appearances of the welds after notched tensile conducted in air, in which the thickness of each specimen after testing is also provided. It can be observed that two triangular-shaped regions of flat fracture are surrounded by the regions of slant fracture for the AW and W1100 specimens as shown in Fig. 8a and d. In contrast, the flat fracture regions are increased considerably for the W900 and W1000 specimens as illustrated in Fig. 8b and c. It was obvious that the notched tensile specimens had different degrees of thickness reduction (the difference between the original and final thicknesses of the specimen). The thickness reduction decreased in the following order: AW, W1100, W1000, and W900 specimens. Furthermore, the sequence was in the increasing order of the hardness or the NTS (in the air) of the specimens. Fig. 8 also
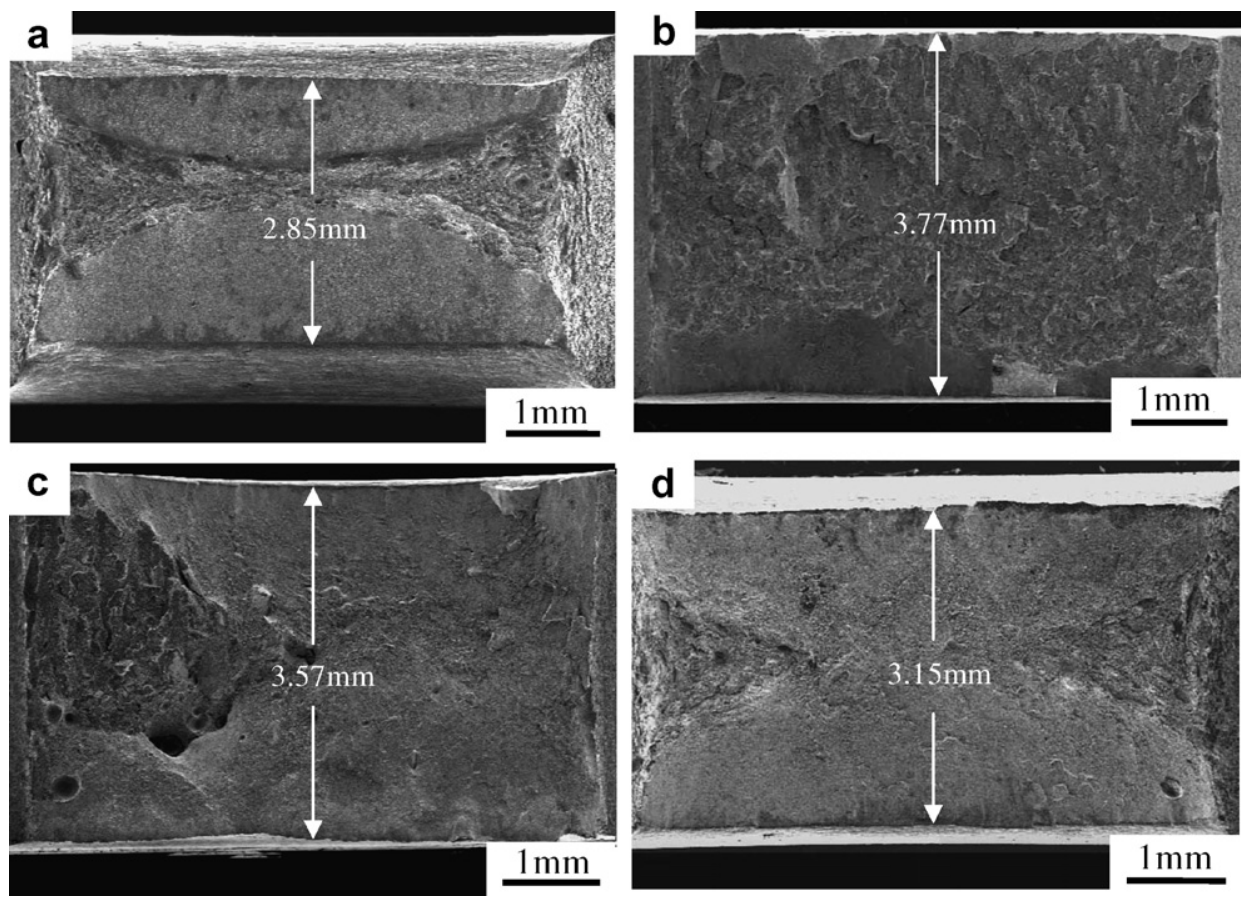

Fig. 8. Macroscopic fracture appearance of the (a) AW, (b) W900, (c) W1000 and (d) W1100 specimens tested in air. 
reveals that lesser the reduction in thickness greater is the flat fracture region of the specimen.

Since the diffusion of hydrogen can be stress-driven, the geometry of the notch tip also plays an important role during straining. The NTS loss in hydrogen was shown to reduce as the notch severity decreased [13]; this could be attributed to an effective decrease in the local hydrogen fugacity [36] and a decreased local stress in the vicinity of a notch. A greater thickness reduction in the AW and W1100 specimens implied that notch blunting (an enlarged plastic zone) would occur before final fracture, leading to a better resistance
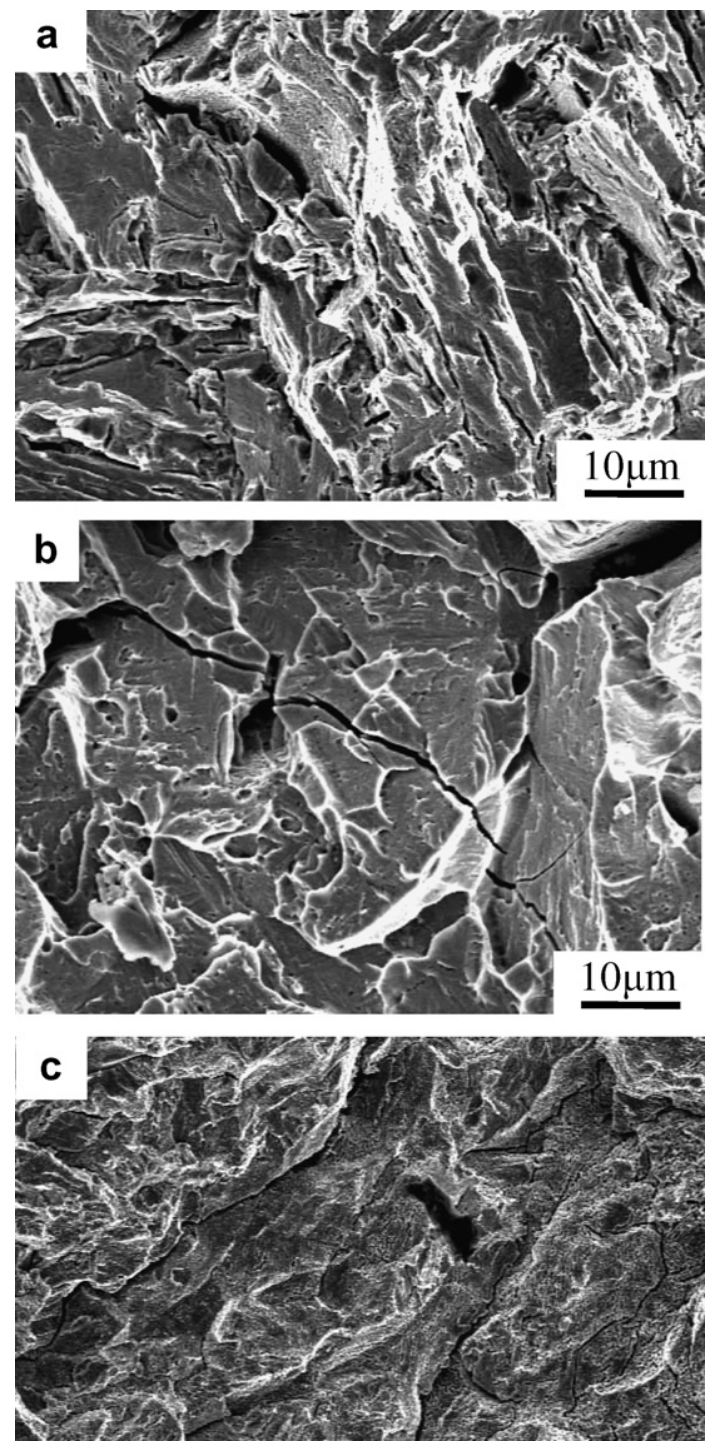

Fig. 9. SEM photographs showing the fracture appearance of the (a) AW, (b) W900 and (c) W1100 specimens after notched tensile tests in saturated $\mathrm{H}_{2} \mathrm{~S}$ solution. 
to SSCC. On the other hand, the W900 and W1000 specimens with less thickness reduction after the notched tensile tests were expected to be more susceptible to SSCC. The foregoing results suggested that the thickness reduction and SSCC susceptibility were closely related. The argument is the similar to the hardness/strength level to affect the local stress and the plasticity at the notch tip of notched specimens as discussed previously.

Aging treatments strongly affected the fractographic appearance of the welds even for the specimens tested in air. The fractographic examinations in the flat fracture region revealed a ductile fracture mode for the AW and W1100 specimens in air, in contrast to the quasi-cleavage fracture for the W900 and reduced quasi-cleavage fracture for the W1000 specimens. For the specimens tested in the saturated $\mathrm{H}_{2} \mathrm{~S}$ solution, an apparent change in the macroscopic fracture morphology was observed. The flat fracture region is known to be most affected by hydrogen and often associated with the changing fracture modes in hydrogen-containing environments [37]. All welds exhibited extensive flat fracture and small thickness reduction, thereby resembling the W900 specimen tested in air (Fig. 8b). The marked change in the macroscopic appearance reflected a severe hydrogen embrittlement of the specimens tested in the saturated $\mathrm{H}_{2} \mathrm{~S}$. solution. Fig. 9 shows the SEM fractographs of the fracture surface of various specimens after notched tensile tests in the saturated $\mathrm{H}_{2} \mathrm{~S}$ solution. All welded specimens displayed mainly quasi-cleavage fracture (Fig. 9a and b), however, the W900 and W1000 specimens appeared to be more brittle and contained more secondary cracks than others. It was interesting to note that a limited region of intergranular fracture (Fig. 9c), which was located just in front of the notch, was observed on the fracture surface of the W1100 specimen. The reason that caused intergranular fracture at the early stage of crack propagation in such a specimen is not clear. However, it could be due to the segregation of impurities to grain boundaries, since sulfur segregation to grain boundaries and intergranular fracture are found in $\mathrm{Cr}-\mathrm{Mo}$ steels tempered at around $600{ }^{\circ} \mathrm{C}[38,39]$. Future works on the segregation of sulfur to grain boundaries in aging treatments, particularly at $593{ }^{\circ} \mathrm{C}$ for $\mathrm{PH} 13-8$ Mo as well as its laser welds are required.

\section{Conclusions}

PH 13-8 Mo welds were susceptible to SSCC at various degrees and exhibited mainly quasi-cleavage fracture after notched tensile tests in the saturated $\mathrm{H}_{2} \mathrm{~S}$ solution. The NTS loss was used to rank the relatively susceptibility to SSCC of the welds. The present investigation on SSCC of the welds aged at distinct temperatures has led to the following conclusion:

1. Both the NTS loss and the hardness of welded specimens increased in the following order: AW, W1100, W1000, and W900 specimens. This sequence was in the decreasing order of the thickness reduction. Notched specimens with lower hardness/strength implied that a lower local stress and a larger plastic zone in front of the notch would be formed, leading to a lower susceptibility to SSCC and vice versa.

2. The decrease in hardness with an increase in aging temperatures $\left(427-593{ }^{\circ} \mathrm{C}\right)$ of the welds was attributed to the formation of reverted austenite and not to the loss of coherency or the coarsening of NiAl precipitates. In case of the W1100 specimen, the more reverted austenite would lower the hardness and the effective diffusion rate for hydrogen, resulting in a reduced SSCC susceptibility. 
3. The AW specimen had the least amount of austenite and the lowest hardness among the specimens being tested. However, the enormous interfaces of austenite films (strong traps leading to reduced hydrogen diffusivity) in a soft matrix (resulting in notch blunting and the low local stress at the notch tip) of the AW specimen would give rise to a lower NTS loss as compared to that of aged specimens.

\section{References}

[1] K. Tsuboi, H. Yatabe, Y. Yamada, Mater. Sci. Technol. 12 (1996) 400-404.

[2] I.O. Shim, J.G. Byrne, Mater. Sci. Eng. A123 (1990) 169-180.

[3] R. Gee, Z.Y. Chen, Corr. Sci. 37 (1995) 2003-2011.

[4] A. Vyrostkova, B. Stefan, Metall. Mater. 28 (1990) 426-432.

[5] D. Hardie, Su'e Liu, Corr. Sci. 38 (1996) 721-733.

[6] T.L. Chang, L.W. Tsay, C. Chen, Mater. Sci. Eng. A316 (2001) 153-160.

[7] Y. Kobayashi, K. Ume, T. Hyodo, T. Taira, Corr. Sci. 27 (1987) 1117-1135.

[8] C.D. Beachem, Metall. Trans. 3 (1972) 437-451.

[9] L.W. Tsay, W.C. Lee, W.C. Luu, J.K. Wu, Corr. Sci. 44 (2002) 1311-1327.

[10] L.W. Tsay, W.B. Huang, Y.M. Li, C. Chen, J. Mater. Eng. Perform. 6 (1997) 177-181.

[11] L.W. Tsay, W.C. Lee, R.K. Shiue, J.K. Wu, Corr. Sci. 44 (2002) 2101-2118.

[12] A.R. Troiano, Trans. ASM 52 (1960) 54.

[13] SU`E Liu, Z. Zhu, K. Wei, J. Mater. Sci. Technol. 12 (1996) 51-56.

[14] B.J. Berkowitz, F.H. Heubaum, Corrosion 40 (1984) 240-245.

[15] R.M. Thompson, G.B. Kohut, D.R. Canfield, W.R. Bass, Corrosion 47 (1991) 216-220.

[16] A. Turnbull, A. Griffiths, Corr. Eng. Sci. Technol. 38 (1) (2003) 21-50.

[17] S. Eliassen, Corr. Eng. Sci. Technol. 39 (1) (2004) 31-37.

[18] A. Turnbull, B. Nimmo, Corr. Eng. Sci. Technol. 40 (2) (2005) 103-109.

[19] R.R. Gaugh, Mater. Perform. 16 (9) (1977) 24-29.

[20] D.H. Ping, M. Ohnuma, Y. Hirakawa, Y. Kadoya, K. Hono, Mater. Sci. Eng. A 394 (2005) 285-295.

[21] V. Seetharaman, M. Sundararaman, R. Krishnan, Mater. Sci. Eng. 47 (1981) 1-11.

[22] P. Munn, B. Andersson, Corrosion 46 (1990) 286-295.

[23] A. Ikeda, T. Kaneko, Y. Ando, Corr. Sci. 27 (1987) 1099-1115.

[24] J.A. Beavers, G.H. Koch, Corrosion 48 (1992) 256-264.

[25] G.T. Murry, H.H. Honegger, T. Mousel, Corrosion 40 (1984) 146-151.

[26] J.R. Scully, M.J. Cieslak, J.A. Van Den Avyle, Scripta Metall. 31 (1994) 125-130.

[27] J.R. Scully, J.A. Van Den Avyle, M.J. Cieslak, A.D. Romig Jr., C.R. Hills, Metall. Trans. 22A (1991) 24292444.

[28] L.W. Tsay, M.Y. Chi, H.R. Chen, C. Chen, Mater. Sci. Eng. A416 (2006) 155-160.

[29] L.W. Tsay, Y.F. Hu, C. Chen, Corr. Sci. 47 (2005) 965-976.

[30] A. Turnbull, R.B. Hutchings, Mater. Sci. Eng. A177 (1994) 161-171.

[31] G.M. Pressouyre, I.M. Bernstein, Acta Metall. 27 (1) (1979) 89-100.

[32] G.M. Pressouyre, I.M. Bernstein, Metall. Trans. 9A (11) (1978) 1571-1580.

[33] J.D. Kordatos, G. Fourlaris, G. Papadimitrious, Scripta Mater. 44 (2001) 401-408.

[34] W.T. Tsai, S.L. Chou, Corr. Sci. 42 (2000) 1741-1762.

[35] W. Zheng, D. Hardie, Corrosion 47 (1991) 792-799.

[36] D. Hardie, P. Bowker, in: A.W. Thompson, I.M. Bernstein (Eds.), Effect of Hydrogen on Behavior of Materials, TMS-AIME, 1976, p. 251.

[37] C.P. Wu, L.W. Tsay, C. Chen, Mater. Sci. Eng. A346 (2003) 302-309.

[38] D.J. Allen, D.A. Wolstenholme, Met. Technol. 9 (7) (1982) 266-273.

[39] C.A. Hippsley, J.F. Knott, B.C. Edwards, Acta Metall. 30 (3) (1982) 641-654. 